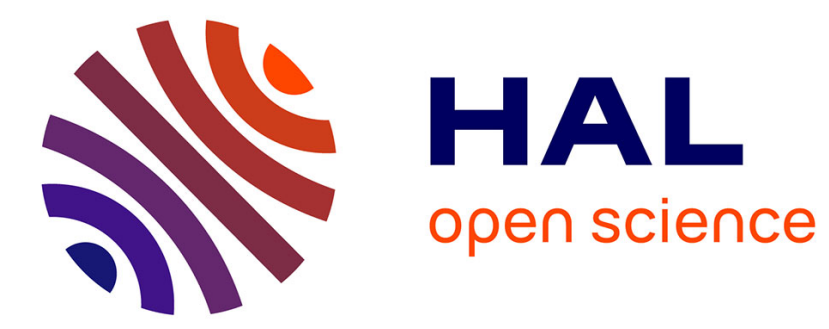

\title{
Willingness-to-pay for road safety improvement
}

Mohamed Mouloud Haddak, Nathalie Havet, Marie Lefèvre

\section{To cite this version:}

Mohamed Mouloud Haddak, Nathalie Havet, Marie Lefèvre. Willingness-to-pay for road safety improvement. 2014. halshs-00950017

\section{HAL Id: halshs-00950017 https://shs.hal.science/halshs-00950017}

Preprint submitted on 20 Feb 2014

HAL is a multi-disciplinary open access archive for the deposit and dissemination of scientific research documents, whether they are published or not. The documents may come from teaching and research institutions in France or abroad, or from public or private research centers.
L'archive ouverte pluridisciplinaire HAL, est destinée au dépôt et à la diffusion de documents scientifiques de niveau recherche, publiés ou non, émanant des établissements d'enseignement et de recherche français ou étrangers, des laboratoires publics ou privés. 
Willingness-to-pay for road safety improvement

Mouloud Haddak, Nathalie Havet, Marie Lefèvre

February 2014 


\section{GATE Groupe d'Analyse et de Théorie Économique Lyon-St Étienne}

93, chemin des Mouilles 69130 Ecully - France

Tel. +33(0)4 72866060

Fax $+33(0) 472866090$

6, rue Basse des Rives 42023 Saint-Etienne cedex 02 - France

Tel. +33 (0)4 77421960

Fax. +33 (0)4 77421950

Messagerie électronique / Email : gate@gate.cnrs.fr

Téléchargement / Download : http://www.gate.cnrs.fr - Publications / Working Papers 


\title{
Willingness-to-pay for road safety improvement
}

\author{
Mouloud HADDAK ${ }^{1}$ \\ UMRESTTE, IFSTTAR \\ Université Lyon 1 \\ Université de Lyon
}

\author{
Nathalie HAVET ${ }^{2}$ \\ GATE Lyon Saint-Etienne, CNRS \\ Université Lumière Lyon 2 \\ Université de Lyon
}

\author{
Marie LEFEVRE ${ }^{3}$ \\ UMRESTTE, IFSTTAR \\ Université Lyon 1 \\ Université de Lyon
}

\begin{abstract}
Few studies have explored, to date, the issue of the monetary valuation of non-fatal injuries caused by road traffic accidents. The present paper arises interest in this question and aims to estimate, by means of the contingent valuation, the willingness to pay (WTP) of French households to improve their road safety level and reduce their risk of non-fatal injuries following a road accident. More precisely, Logit and Tobit models will be estimated to identify the factors influencing the individual will to pay. The results highlight the significant and positive influence of the injury severity on the WTP of the participants. The direct or indirect experience of road traffic accidents seems to play an important role and positively influences the valuation of the non-fatal injuries.
\end{abstract}

\section{Résumé}

Disposition à payer pour améliorer la sécurité routière : Jusqu'à présent, peu d'études se sont focalisées sur l'évaluation monétaire des blessures non-mortelles causées par des accidents de la route. Cet article s'y intéresse et cherche à estimer, grâce à une évaluation contingente, la disposition à payer (DAP) des ménages français pour améliorer le niveau de sécurité sur les routes et réduire le risque de blessures non-mortelles liées aux accidents de la route. Plus précisément, des modèles logit et tobit ont été estimés pour identifier les facteurs influençant la disposition à payer des individus. Les résultats mettent en évidence que les DAP individuelles sont significativement croissantes avec la sévérité de la blessure. Par ailleurs, le fait d'avoir été directement ou indirectement confronté à un accident de la route semble jouer un rôle important puisque cela influence aussi positivement les DAP.

Keywords : Road safety; Willingness to pay; Contingent valuation; Value of risk reduction; serious injuries

JEL classification : R41, C24.

\footnotetext{
${ }^{1}$ Epidemiological Research and Surveillance Unit in Transport, Occupation and Environment (UMRESTTE), French Institute of Science and Technology for Transport, Development and Networks (IFSTTAR), Cité des Mobilités, 25 avenue François Mitterrand, F-69675, Bron, France ; Université de Lyon, F-69622, Lyon, France ; Université Lyon 1, UMRESTTE, F-69373, Lyon, France. Email : mouloud.haddak@ifsttar.fr

${ }^{2}$ Université de Lyon, Lyon, F-69007, France ; CNRS, GATE Lyon St Etienne, Ecully, F-69130, France, Université Lyon 2, Lyon, F-69007, France. GATE: 93, Chemin des Mouilles, B.P. 167, 69131 Ecully, France. Tél : 04728660 83. Fax : 04728660 90. E-mail: havet@gate.cnrs.fr.

${ }^{3}$ Epidemiological Research and Surveillance Unit in Transport, Occupation and Environment (UMRESTTE), French Institute of Science and Technology for Transport, Development and Networks (IFSTTAR), Cité des Mobilités, 25 avenue François Mitterrand, F-69675, Bron, France ; Université de Lyon, F-69622, Lyon, France ; Université Lyon 1, UMRESTTE, F-69373, Lyon, France. Email : marie.lefevre@ifsttar.fr
} 


\section{Introduction}

Road safety lies at the heart of several and critical issues. Road accidents create serious consequences, in both economic and public health levels. These include loss of productive capacity and income or human resources following a road accident. If we add to this the damage to property, medical care and related rehabilitation, the burden resulting from road accidents quickly becomes considerable.

Globally, the cost of traffic accidents represents $1-3 \%$ of the gross national product of countries and road accidents would rank as the fifth leading cause of death by 2030 if no significant progress in terms of road safety rapidly occurs (WHO, 2009).

Aware of these issues, most of the European countries have achieved significant progress in this area over the years, especially within the European Union since the White Paper on European transport policy ${ }^{4}$ and, since 2002 in France, when road safety has been set up as a major national cause.

The decrease of the number of people injured and killed on the roads in recent decades partly reflects the effectiveness of the implemented measures. It is important to keep in mind that road safety devices represent a significant financial burden on the government budget as well as household budgets. This last consideration certainly explains the recent interest of policy decision-makers in tools of assessment and prioritisation of both transport and infrastructure projects. Such tools particularly suppose the monetary quantification of the benefits associated with road safety measures.

Basically, the economic assessment of road safety devices raises the problem of the valuation methods used. If the estimation of the damages avoided by the introduction of a road safety measure is relatively easy and explicit, the valuation of risk reductions on health and human life that it generates is more delicate. An extensive literature has examined this issue and tried to estimate the value associated with a reduced risk of injury, whether mild or fatal, resulting from a road accident. Since the 1980s, an important step was made on the monetary valuation method to use.

The somewhat controversial human capital approach (Arthur, 1981; Jeremic et al., 2012; Jones-Lee and Loomes, 2003) has been gradually abandoned. This method had significant limitations because it only aimed to estimate the damages (dead or injured) according to their unique economic impact, that is to say, mainly in terms of loss of production. The intrinsic value of the damage and the suffering resulting from the injury or the loss of a human life was completely hidden. It is from this observation that a focusing approach appeared on individual preferences and perceptions; the method of the willingness to pay (WTP) (Mishan, 1971; Weinstein et al., 1980). The WTP is defined therefore as the maximum amount of money a subject is willing to pay to reduce his risk of premature death or personal injury due to the practice of a risky activity; in our study case road traffic.

Two methods for estimating the willingness to pay coexist: the revealed preference methods and the stated preference methods. The first is based on the observation of the current behaviour of subjects in their daily activity, whether making consumption or investment, to infer the value to non-market goods.

Thus, the study of the individuals' behavior in the car market has helped to highlight the arbitration made by people between wealth and physical risk (Andersson, 2005; Andersson and Svensson, 2008; Atkinson and Halvorsen, 1990; Dreyfus and Viscusi, 1995). The stated preference methods, in turn, differ from previous ones by their hypothetical character. There is no question of observing actions on

\footnotetext{
${ }^{4}$ The White paper, presented by the European Committee on September 12 ${ }^{\text {th }}$ 2001: "European transport policy for 2010: time to decide". This white paper was accompanied by a new action plan on the road safety for period 2002-2010 aiming to reduce by half the number of deaths on the road.
} 
existing markets but rather intentions of purchase or investment. These methods consist in exposing the agents to virtual scenarios in which the good assessed is subject to change.

The most common stated preference method in the literature is the technique of the contingent valuation. Respondents are asked the maximum amount of money they are willing to pay for a variation of the good of interest (Beattie et al., 1998; Carthy et al., 1998) . It is thus possible to directly obtain the value that subjects are willing to spend to improve their road safety level and determine, more broadly, the value they infer to a healthy life without injury.

The present study consists in the valuation of non-fatal injuries, more or less serious, caused by traffic accidents. More specifically, it is to estimate the willingness to pay of road users to reduce their risk of being victim of various types of non-fatal injuries. To do this, a contingent valuation has been conducted on the adult population of the Rhône (France) during the year 2012.

The aim of our approach is manifold. Firstly, we try to determine whether there is a relationship between the individual willingness to pay and the severity of the injuries. Secondly, we also test whether the willingness to pay depends on the level of risk reduction. Finally, we will study the socioeconomic factors that may be involved in the determination of the willingness to pay of road users.

The rest of the paper is organised as follows. The second section deals with the materials and methods used to conduct the study. The third section will provide an overview of the results. Finally, we will discuss the results in a fourth section, before concluding the study and its perspectives.

\section{Material and methods}

\subsection{Participants}

The population targeted in this study is the residents of the department of the Rhône. This population has been classified into two categories called "cases" and "controls". Members of the "cases" group are the inhabitants of the Rhône, aged 18 years and older, victims of a road accident that resulted in personal injury in 2010. Their population was randomly selected from the Rhône Road Trauma Registry ${ }^{5}$. Individuals included in the "controls" group are the inhabitants of the Rhône, aged 18 years and older, not personally victims of a crash resulting in death or injury during or after the year 2010 . Their selection was randomly made from the electoral lists of the Rhône, excluding the individuals present in the previous register for the year 2010. This double selection, "cases" and "controls", allows us to ensure that part of the studied population recently faced up to road traffic personal injuries (in 2010) and to test the assumption that the recent occurrence of a road traffic injury affects the willingness to pay of individuals to improve their road safety level. A total of 600 individuals in the group of "cases" and 1,792 individuals in the "controls" group were selected for a total sample of 2,392 subjects.

\subsection{Procedure}

The questionnaires were mailed by post. The study consisted more specifically in sending two sets of questionnaires: "Serie 1" and "Serie 2". In "Serie 1", subjects had the possibility to reduce their risk of experiencing various non-fatal types of injuries following a road accident by $25 \%$. This reduction was fixed to $50 \%$ in "Serie 2" of the questionnaire. This approach allows us to test the participants

\footnotetext{
${ }^{5}$ The Rhône Road Trauma Registry records all casualties, injured or killed, in and outpatients since 1995.
} 
'sensitivity to the level of reduction of the risk accidents and to study whether their WTP to improve their road safety increases with this level. The literature has shown that the WTP remains invariant regardless of the level of improvement proposed (Beattie et al., 1998; Hammitt and Graham, 1999). This insensitivity, apparently surprising, more commonly named scale bias, is explained by the difficulty of individuals to evaluate and distinguish small changes in risk (Carson et al., 2001). A recent Swedish study showed that such a bias was more present among respondents with low cognitive ability to understand and distinguish the statement of low probabilities (Andersson and Svensson, 2008).

In order to limit the emergence of scale bias in our study, additional information is given to the subjects. They are informed about the number of victims of various non-fatal types of injury each year in the Rhône department. They're also given, for each type of injury, the number of people saved if the risk of accidents was reduced by $25 \%$ or $50 \%$ (depending on the set of questionnaires they receive). This information allows the participants to concretely measure the consequences of the risk reduction and to better understand this notion of risk.

Apart from this change in the risk reduction of road accident $(25 \%$ or $50 \%)$, the two sets of questionnaires are strictly identical. Within each of the two sub-samples "cases" and "controls", the two sets of questionnaires were randomly distributed in equal numbers among the participants. Each individual only received one set.

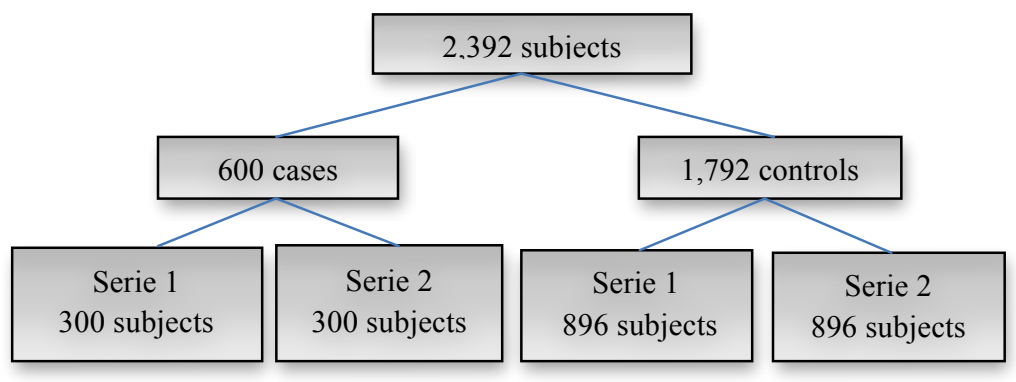

Figure 1. Administration of the sets of questionnaires to subjects.

\subsection{Questionnaire Design}

The questionnaire contains five categories of questions: (1) personal experience in dealing with road accidents, (2) driving behaviour and risk perception of traffic accident, (3) use of means of transport (4) general socio-economic characteristics, (5) willingness to pay of individuals to reduce the risk of non-fatal injuries following a road traffic accident. The content of each of these categories is explained in more details below.

(1) Personal experience of traffic accidents

We distinguish direct experiences, that is to say people personally injured after a road accident, from indirect ones through the family or their immediate circle.

(2) Behaviour on the road and perceived risk of accident

We collect information on the behaviour of individuals as road users and the way they perceive the risk of road accidents. It includes determining how the individuals behave when facing the risk of accidents and how they assess their own risk of accident.

\section{(3) Use of transportation means}


This focus allows us to describe transport practices including mobility issues, the modes of transport the most frequently used by the individuals and the possible divergence of travel patterns between weekdays and weekends.

(4) General socio-economic characteristics

This section aims to gather general information on age, sex, place of residence, family and professional status of individuals, and thus to assess their socioeconomic status.

(5) Willingness to pay of individuals

This part is the heart of the contingent valuation. It requires the establishment of a fictional scenario, however realistic and intelligible, from which individuals will be called to reason. Then, they will have to express how much they would be willing to pay to reduce their risk of experiencing various non-fatal types of injuries following a road accident. The level of the risk reduction depends on the set of questionnaires, which was assigned to the individuals (Figure $1)$.

The participants have the possibility to financially contribute to the implementation of a local project, which aims to strengthen the safety of road users within the department of the Rhône. Since the participants are themselves inhabitants of the Rhône, they should feel immediately concerned by a project within their own department for their routine travels. An increase in local taxes in the department is used as means of payment. This increase would take the form of a special tax of a fixed amount to be paid once a year by the inhabitants for 3 years. The impact of a financial contribution on the participants' budget is also pointed out. This last remark aims to draw attention to the economic commitments arising from a possible contribution to the project and thus attempts to limit the presence of hypothetical bias (Harrison, 2006; Hofler and List, 2004).

To test the possible relationship between the WTP and the severity of the injuries, three road safety projects are then independently presented to the respondents. Each project is characterized by the types of injuries against whom it protects. The respondent is also informed about his baseline risk of being a victim of each kind of injury.

The three projects presented to the subjects are as follows: (a) Project A reduces the risk of being a victim of a road accident causing minor injuries such as whiplash and psychosomatic disorders (memory loss, headaches, nightmares...), (b) Project B reduces the risk of being a victim of a traffic accident resulting in serious injuries such as paralysis or quadriplegia, (c) Project $\mathrm{C}$ reduces the risk of becoming a victim of a road accident resulting in moderate injuries such as thoracic fractures, orthopaedic and ligament injuries with motricity damage.

For each project, the respondents are asked whether they are ready to pay for the project to be implemented. If the subject agrees, we collect the maximum amount of money, in euros, he is willing to pay each year. Otherwise, we assign him a zero WTP and we introduce a follow-up question to determine the grounds for refusal. It allows us to distinguish "genuine zero values" consistent with economic decision from protest responses (Strazzera et al., 2003). Respondents may genuinely place zero values on a project, through stating that they have no strong (nil or very small) preference for it or cannot afford to pay. Their responses are thus consistent with their preferences. In contrast, protest responses do not reflect individual preferences and have no economic significance (Jorgensen et al., 1999; Lindsey, 1994). Protest responses can result from emotional and ethical concerns, as well as from social responsibility consideration (Jorgensen et al, 2000; Meyerhoff and Liebe, 2006). They may reflect participants 'objection to being asked to fill questionnaires, or indicate an ideological position about the inappropriateness of placing monetary values on road safety. Consequently, protest 
individuals refuse to reveal their real WTP even though it is positive. In practice, seven grounds for refusal are proposed: (1) the project to me seems useless, (2) I do not have the financial means to contribute to the project, (3) I do not feel concerned by the subject, (4) it is not my responsibility to pay, (5) I don't have enough information to make a decision, (6) I do not want to pay for others (7) I don't know. The zero responses justified by the first three reasons are considered as "true zeros" while others are considered as protest responses.

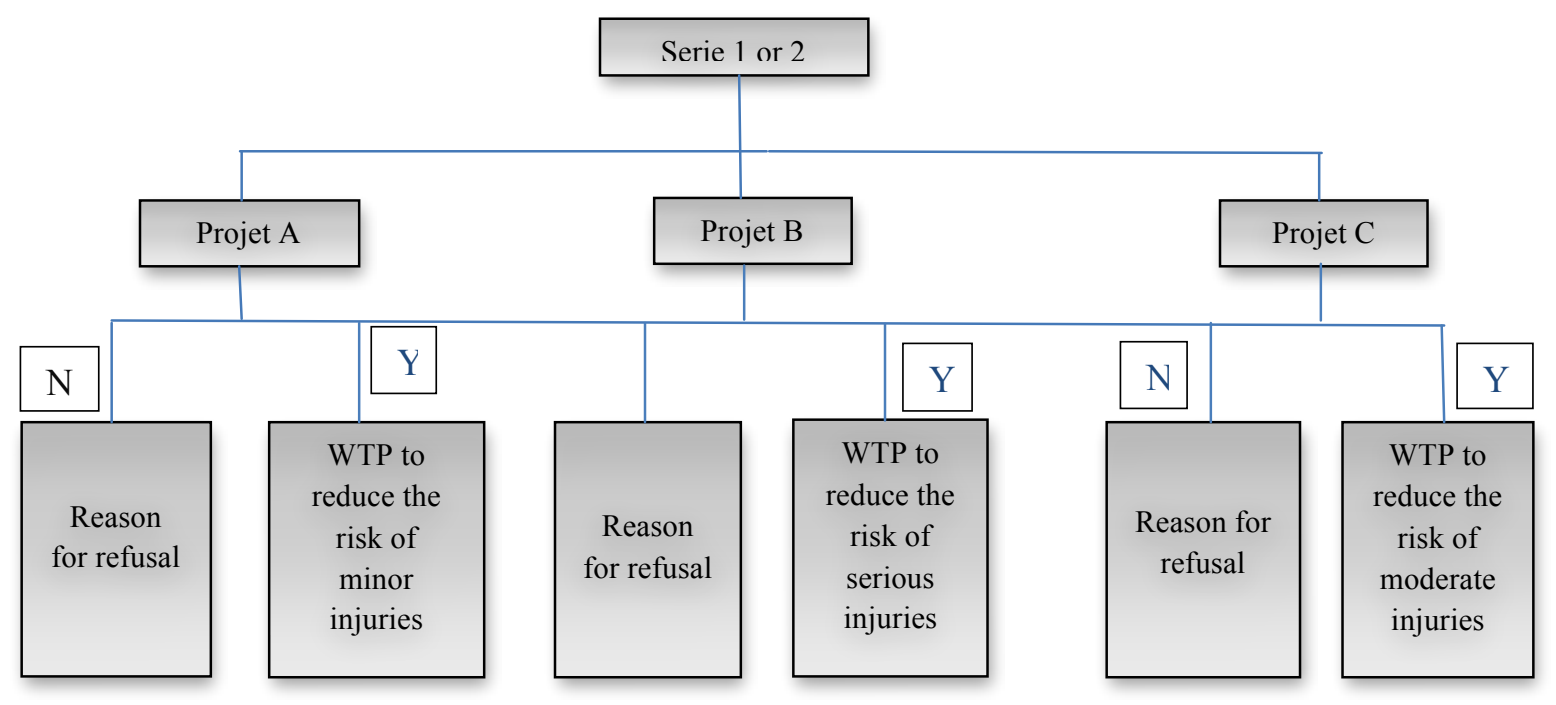

Figure 2. Flow diagram of the contribution decisions of the participants for each project ( $\mathrm{Y}=\mathrm{yes}, \mathrm{N}=\mathrm{no})$.

\subsection{Econometric specifications}

Multivariate econometric models were estimated to explore the possible determinants of WTP for a risk reduction of road traffic injuries (age, gender, household income, presence of young children within the household, experience of road accidents, level of accident risk reduction, severity of the injuries, perception of traffic accidents, pattern and main mode of transport during the week) and analyse the relation between the WTP and predictor variables. For example, since the economic theory suggests that income positively influences WTP values, a positive association between WTP and income was assessed to determine the construct validity of our survey.

Zero values should receive particular attention in this econometric analysis, as it is usually the case in the CV literature. Not only the individuals giving zero responses could represent an important proportion of the whole sample, but there was also a range of possible explanations for zero values, from true zero responses to protest responses. Consequently, we decomposed our econometric analysis of the individual behaviour in the decision-making process in two parts: first, the reasons for deciding to accept or not to pay to improve road safety and reduce the risk of injury (participation equation) and second, the decision on the amount of money the individuals are willing to pay for this risk reduction. A Logit regression is also first estimated for the dichotomous variable $I$, to examine the impact of the predictors $X_{i} \delta$ on the probability of recording a positive WTP value:

$$
I_{i}=X_{i} \delta+u_{i}, u_{i} \rightarrow V(0,1), \text { with } V \text { the logistic distribution function, }
$$


If $I_{i}>0$ then we observe $y_{i}>0$, if $I_{i} \leq 0$ then we observe $y_{i}=0$.

The second step is a Tobit regression on the natural logarithm of the dependent variable $y$ since the WTP data observed were censored. The large proportion of zero WTP responses (see section Results) called into question the continuity of the dependent variable and consequently the use of the standard linear regression model. In the presence of censored data, OLS estimation would yield biased and inconsistent estimates because it fails to account for the qualitative difference between limit (zero) observations and non-limit (continuous) observations. The Tobit model is then the alternative method frequently proposed on the literature on contingent valuation (Donaldson et al., 1995).

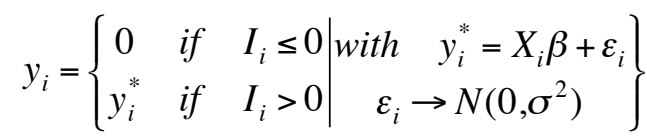

To take into account that zero WTP values include both "genuine zeros" and "protest responses", the logit and Tobit models were estimated in two different ways depending on the inclusion or exclusion of respondents judged as protesters.

\section{Results}

\subsection{Sample characteristics}

194 individuals agreed to participate and sent back the completed survey that is to say a response rate of about $10 \%$ (see Table 1 ).

Table 1. Distribution of participants and scenarios .

\begin{tabular}{llll}
\hline & Total sample & Cases subsample & Controls subsample \\
\hline Number of participants & $194(100)$ & $31(15,98)$ & $163(84,02)$ \\
Scenario 1 & $115(59,28)$ & $14(45,16)$ & $101(61,96)$ \\
Scenario 2 & $79(40,72)$ & $17(54,84)$ & $62(38,04)$ \\
Response rate (in \%) & 10,21 & 6,68 & 11,34 \\
\hline
\end{tabular}

Note: The response rate is calculated by taking into account returns of mails because of erroneous addresses. The percentages of respondents in each category are given in parentheses.

Table 2 presents the sample characteristics. The participants are mainly aged 45-64 years old (58\%) and mainly declare to live within a household whose monthly net income is between 2000 and 4000 euros (45\%). About a third of the participants (34\%) declare to live within a household with at least two children under 18 against $19 \%$ for children under 14 . Concerning their common trip, the majority of the individuals declare to travel mainly by car (53\%). A great majority of the participants $(72 \%)$ class the access to their place of work or studies as their main motive to travel. Few participants claim to have been indirectly confronted to a traffic accident during the last 12 months. Only $18 \%$ of them know a person of their immediate entourage who was hurt or killed in a road accident during the last 12 months. Concerning their apprehension of road accidents, $77 \%$ of the participants admit to being worried or terrified when talking about road accidents and declare that they take into account this feeling of insecurity in their current travels. Globally, theses tendencies remain stable between the "cases" and "controls" groups. It is worth noting that the participants belonging to the "cases" subsample show themselves to be more anxious in the evocation of road accidents than the "controls" group (94\% against $74 \%$ ) and more often use a bike or a motorized two-wheelers as main mode of transportation (19\% against $8 \%$ ). 
Table 1. Sample characteristics.

\begin{tabular}{|c|c|c|c|}
\hline & Total sample & Cases subsample & Controls subsample \\
\hline \multicolumn{4}{|l|}{ Gender } \\
\hline Female & $103(53,09)$ & $17(54,84)$ & $86(52,76)$ \\
\hline Male & $91(46,91)$ & $14(45,16)$ & $77(47,24)$ \\
\hline \multicolumn{4}{|l|}{ Age } \\
\hline $18-24$ & $15(7,73)$ & $3(9,68)$ & $12(7,36)$ \\
\hline $25-44$ & $40(20,62)$ & $9(29,03)$ & $31(19,02)$ \\
\hline $45-64$ & $113(58,25)$ & $18(58,06)$ & $95(58,28)$ \\
\hline$>=65$ & $26(13,40)$ & $1(3,23)$ & $25(15,34)$ \\
\hline \multicolumn{4}{|l|}{ Average monthly net income (euros) } \\
\hline$<=2000$ & $40(20,62)$ & $6(19,35)$ & $34(20,86)$ \\
\hline ] $2000-4000]$ & $88(45,36)$ & $16(51,61)$ & $72(44,17)$ \\
\hline$>4000$ & $66(34,02)$ & $9(29,03)$ & $57(34,97)$ \\
\hline \multicolumn{4}{|l|}{ Household } \\
\hline Presence of children under 18 & $65(33,51)$ & $8(25,81)$ & $57(34,97)$ \\
\hline Presence of children under 14 & $37(19,07)$ & $6(19,35)$ & $31(19,02)$ \\
\hline \multicolumn{4}{|l|}{ Perception of road accidents } \\
\hline Indifferent / little worried & $45(23,20)$ & $2(6,45)$ & $43(26,38)$ \\
\hline Very worried/ Terrified & $149(76,80)$ & $29(93,55)$ & $120(73,62)$ \\
\hline $\begin{array}{l}\text { Presence of immediate entourage injured in the } \\
\text { last } 12 \text { months }\end{array}$ & $35(18,04)$ & $7(22,58)$ & $28(17,18)$ \\
\hline \multicolumn{4}{|l|}{ Main mode of transportation } \\
\hline Car & $112(53,08)$ & $16(51,61)$ & $95(58,28)$ \\
\hline Bike / motorized two-wheelers & $20(9,48)$ & $6(19,35)$ & $13(7,98)$ \\
\hline Public transport & $47(22,27)$ & $6(19,35)$ & $31(19,02)$ \\
\hline Walking & $32(15,17)$ & $3(9,68)$ & $24(14,72)$ \\
\hline \multicolumn{4}{|l|}{ Main travel purpose } \\
\hline Compelling reasons (work, studies...) & $139(71,65)$ & $26(83,87)$ & $113(69,33)$ \\
\hline $\begin{array}{l}\text { Non-compelling reasons (shopping, spare time, } \\
\text { visits...) }\end{array}$ & $55(28,35)$ & $5(16,13)$ & $50(30,67)$ \\
\hline
\end{tabular}

Note: The percentages of respondents in each category are given in parentheses.

\subsection{Rate of contribution}

Among the 194 participants, 118 persons declared not to be ready to financially contribute to the project $\mathrm{A}$ affecting the reduction of the risk of minor injuries and 116 participants refused to financially contribute to the project $\mathrm{C}$ aiming to reduce the risk of moderate injuries. This number of zero WTP falls to 89 if we consider the project B dealing with severe injuries. It is possible to refine the analysis by distinguishing "true zero responses" from "protest responses". The distribution of "true zeros" versus "protest zeros" is relatively stable between the projects $\mathrm{B}$ and $\mathrm{C}$ (with a rate of protest respectively equals to $73 \%$ and $71 \%$ among the participants who refuse to contribute to the projects). This proportion of protest responses falls $(57 \%)$ when we consider the project A concerning minor injuries. We can also assume that the proportion of the individuals who refuse to contribute to the project A by real disinterest is more important than for other projects. A more detailed study of the motivations of no contribution confirms this reasoning. Whatever the project is, three causes of refusal arrive in head: "it is not my responsibility to pay", "I don't have enough information to make a decision" and "the project to me seems useless ". On the other hand, their hierarchy is different from 
one project to another. While the uselessness arrives in head for the project A with $31 \%$ of the answers, it takes place in the third position for the projects $\mathrm{C}$ and $\mathrm{B}$ with respective scores of $23 \%$ and $17 \%$.

For each project, figure 3 represents the refusal rate with and without the protesters. It is worth noting that the rates of refusal decrease with the severity of injuries. While the refusal rates, after exclusion of protesters, respectively reach $30 \%$ and $39 \%$ for moderate and minor injuries, this rate falls to $19 \%$ when we consider severe injuries.

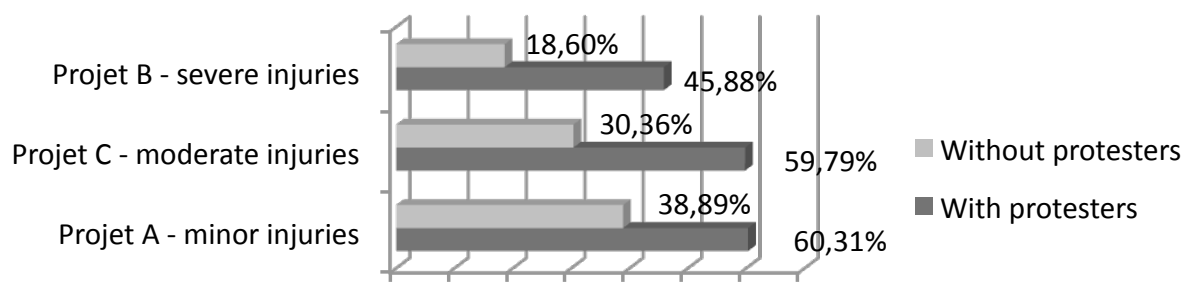

0\% $10 \% 20 \% 30 \% 40 \% 50 \% 60 \% 70 \%$

Figure 3. Refusal rates by project.

\subsection{Stated WTP values}

Table 3 represents the average individual contributions to the various projects. Whatever the angle of view, there is no statistically significant difference between the average contributions to the projects $\mathrm{A}$ and $\mathrm{C}(\mathrm{P}=0,1651$ for the positive contributions; $\mathrm{P}=0,1826$ for the contributions with protesters and $\mathrm{P}=0,0668$ for the contributions without protesters) while the average contributions to the project $\mathrm{B}$ are significantly higher $(\mathrm{P}=0,007$ for the positive contributions, $\mathrm{P}<0,001$ for the contributions with or without protesters). On average, an individual is ready to pay more to protect himself from the risk of severe injuries in comparison to minor and moderate ones.

Table 2.Average willingness to pay by project.

\begin{tabular}{lccc}
\hline & - projet A $~$ & - projet C - & - projet B - \\
Minor injuries & Moderate injuries & Severe injuries \\
\hline Average positive contributions & $40,37 €$ & $38,51 €$ & $45,19 €$ \\
Average contributions including protesters & $15,51 €$ & $15,10 €$ & $23,68 €$ \\
Average contributions without protesters & $24,07 €$ & $26,50 €$ & $36,30 €$ \\
\hline
\end{tabular}

\subsection{The determinants of WTP}

Table 4 presents the estimations results of the Logit and Tobit models (equations 1 and 2) estimated with and without protesters' answers. The high number of individuals refusing to pay for the projects (figure 3), and so having a zero WTP, confirms the censorship of the data and pleads for the use of a Tobit model.

As expected, income is positively connected to the WTP in both Logit and Tobit models. The more the household income is high, the more the contribution probability is important and the more the amount of the contribution is high. The fact that this income effect was confirmed in our two models argued in favour of the construct validity of our survey. 
The determinants of the participants' contribution decision (model Logit) are globally similar to the factors occurring in the determination of the amount of the contribution (model Tobit) with the exception of the variable "main travel purpose". This variable is exclusively significant in the Logit model and so only seems to influence the individual decision of contribution. More specifically, the individuals who mainly travel for non-compelling reasons (shopping, leisure, visits, etc.) have a lower probability to agree to financially contribute to improve their level of road safety than the individuals mainly moving for compelling reasons (work, studies). On the other hand, this variable "main travel purpose" seems to have no significant impact on the amount of the WTP.

We can note that the exclusion of the protest answers doesn't consequently change the results. Whatever the model, the severity of injuries takes place as a decisive factor (significant at the $1 \%$ level) in the individual contributions that it is about decisions of contribution or the declared amount of money. Indeed, the respondents show themselves more ready to financially invest in road safety measures when they protect them from severe injuries in comparison to minor and moderate ones. As an example, among the sample of the individuals considered as no protesters, a subject with the most collectively met characteristics (see table 2), has a predicted probability of $92 \%$ to agree to financially contribute to the project $\mathrm{B}$ against $76 \%$ and $84 \%$ for the projects $\mathrm{A}$ and $\mathrm{C}$ respectively.

The accidental experience of the individuals, direct as indirect, has also a significant influence on the process of contribution. The probability to invest, as well as the amount of the investment, is more important when the individuals or their close relatives had already been hurt in a traffic accident in the recent past. A test of Wald performing after each of the Logit and Tobit regressions puts in light the similar impact of these two events on the process of contribution $(\mathrm{P}>0,50)$ : other things being equal, an individual who was hurt during a road accident has an identical probability of contribution and tends to declare a similar amount of money than an individual whose immediate entourage was recently injured in a road accident. Consequently, the WTP for a risk reduction of physical injuries does not exclusively depends on the fact of having personally been a victim of a traffic accident but also depends on the fact of knowing a person in a close circle recently hurt during a road accident. 


\begin{tabular}{|c|c|c|c|c|}
\hline \multirow[t]{2}{*}{ Variables } & \multicolumn{2}{|c|}{ Logit } & \multicolumn{2}{|c|}{ Tobit } \\
\hline & With protesters & Without protesters & With protesters & Without protesters \\
\hline \multicolumn{5}{|l|}{ Severity of injuries } \\
\hline Minor & Ref. & Ref. & Ref. & Ref. \\
\hline Moderate & $0.025(0.18)$ & $0.467\left((1.88)^{*}\right.$ & $-0,005(-0,02)$ & $0,426(1,80)^{*}$ \\
\hline Severe & $0.685(3.96)^{* * *}$ & $1.304(4.23)^{* * *}$ & $1,151(3,97) * * *$ & $1,150(4,25)^{* * *}$ \\
\hline Cases group & Ref. & Ref. & Ref. & Ref. \\
\hline Controls group & $0.552(1.51)$ & $1.415(2.65)^{* * *}$ & $1,268(2,15)^{* *}$ & $1,405(3,94)^{* * *}$ \\
\hline Scenario 1 & Ref. & Ref. & Ref. & Ref. \\
\hline Scenario 2 & $-0.087(-0.30)$ & $-0.307(-0.86)$ & $-0,009(-0,02)$ & $-0,194(-0,60)$ \\
\hline \multicolumn{5}{|l|}{ Age } \\
\hline $18-24$ & $1.163(1.60)$ & $0.251(-0.28)$ & $1,944(1,57)$ & $-0,085(-0,10)$ \\
\hline $25-44$ & $0.909(1.41)$ & $0.699(-0.79)$ & $1,184(0,97)$ & $-1,099(-1,24)$ \\
\hline $45-64$ & $0.346(0.63)$ & $0.271(-0.39)$ & $0,534(0,50)$ & $-0,588(-0,78)$ \\
\hline$>=65$ & Ref. & Ref. & Ref. & Ref. \\
\hline \multicolumn{5}{|l|}{ Gender } \\
\hline Female & Ref. & Ref. & Ref. & Ref. \\
\hline Male & $-0.203(-0.70)$ & $-0.359(-0.81)$ & $-0,228(-0,45)$ & $-0,247(-0,74)$ \\
\hline \multicolumn{5}{|c|}{ Average monthly net income (euros) } \\
\hline$<=2000$ & Ref. & Ref. & Ref. & Ref. \\
\hline ]2000 - 4000] & $1.435(3.68)^{* * *}$ & $1.773(3.64)^{* * *}$ & $2,562(3,83)^{* * *}$ & $1,985(4,07)^{* * *}$ \\
\hline$>4000$ euros & $1.017(2.43)^{* *}$ & $1.102(2.21)^{* *}$ & $1,894(2,49)^{* *}$ & $1,560(2,85)^{* * *}$ \\
\hline \multicolumn{5}{|l|}{ Presence of children under 14} \\
\hline No & Ref. & Ref. & Ref. & Ref. \\
\hline Yes & $-0.057(-0.15)$ & $0.335(0.66)$ & $0,044(0,06)$ & $0,418(0,97)$ \\
\hline No response & $1.278(2.45)^{* *}$ & $0.384(0.55)$ & $1,456(1,57)$ & $-0,273(-0,38)$ \\
\hline \multicolumn{5}{|l|}{$\begin{array}{l}\text { Presence of Injured immediate } \\
\text { entourage }\end{array}$} \\
\hline No & Ref. & Ref. & Ref. & Ref. \\
\hline Yes & $0.711(1.89)^{*}$ & $1.756(2.71)^{* * *}$ & $1,221(2,05)^{* *}$ & $1,127(3,47)^{* * *}$ \\
\hline \multicolumn{5}{|l|}{ Perception of road accidents } \\
\hline Indifferent / little worried & Ref. & Ref. & Ref. & Ref. \\
\hline Very Worried & $0.576(1.70)^{*}$ & $0.541(1.37)$ & $1,069(1,74)^{*}$ & $0,458(1,10)$ \\
\hline \multicolumn{5}{|l|}{ Main travel purpose } \\
\hline Compelling & Ref. & Ref. & Ref. & Ref. \\
\hline Non compelling & $-0.695(-1.85)^{*}$ & $-0.815(-2.12)^{* *}$ & $-0,934(-1,34)$ & $-0,531(-1,22)$ \\
\hline \multicolumn{5}{|l|}{ Main mode of transportation } \\
\hline Car & Ref. & Ref. & Ref. & Ref. \\
\hline Bike / motorized two-wheelers & $-0.178(-0.35)$ & $0.424(0.71)$ & $-0,617(-0,70)$ & $-0,101(-0,22)$ \\
\hline Public transport & $0.189(0.52)$ & $-0.172(-0.30)$ & $0,314(0,50)$ & $-0,213(-0,49)$ \\
\hline Walking & $-0.175(-0.42)$ & $0.187(0.42)$ & $-0,238(-0,31)$ & $0,159(0,36)$ \\
\hline Intercept & $-2.137(-1.75)^{*}$ & $-0.293(-0.21)$ & $-4,135(-1,89)^{*}$ & $0,329(0,24)$ \\
\hline $\mathbf{N}$ & 582 & 367 & 567 & 353 \\
\hline
\end{tabular}

Table 3. Estimated Logit and Tobit models.

Notes: t Student are in parentheses. ${ }^{* *}, * *$ and $*$ represent the significance level at $1 \%, 5 \%$ and $10 \%$ respectively. 
The way the individuals perceive traffic accidents, and more exactly their degree of anxiety, also seems to come into play in the decision of contribution but exclusively when the protest individuals are not removed from the models. Indeed, the individuals declaring themselves worried or terrified in the evocation of road accidents have a superior probability of contribution than the individuals who declare to be indifferent or of a little worry.

On the other hand, table 4 shows that the probability of contribution is independent from the level of risk reduction $(\mathrm{P}=0,762$ and $\mathrm{P}=0,391$ with and without protesters respectively). This remark also applies to the individual WTP which doesn't seem to be impacted by the level of risk $(\mathrm{P}=0,770$ and $\mathrm{P}=0,547$ with and without protesters respectively). In spite of the precautions we take to illustrate the consequences related to the different levels of risk reduction $(25 \%$ or $50 \%)$, it seems to persist a scale bias, often pointed out in the literature. Moreover, the age and the main mode of transportation are not factors significantly influencing the WTP. These various groups would have, a priori, relatively similar preferences, any things being equal besides, in terms of improvement of road safety.

Independent Logit and Tobit regressions, for each of the three projects, were performed and allowed to specify certain results. For example, they highlighted that worried or terrified persons in front of road accidents seem to be more ready to invest in road safety projects but only if the project reduces the risks of heavy physical injury. Indeed, this variable of perception is not significant when we restrict our study to projects concerning minor or moderate injuries. Also, in our separate regressions, the positive influence of an injured immediate close circle on the WTP is well verified for the projects associated to the risks of moderate or severe injuries but is absent when talking about minor injuries.

\section{Conclusion}

The monetary quantification of profits associated with road safety measures was for a long time limited to the valuation of the number of avoided deaths. An important part of the literature focused on the estimation of the WTP for a reduction of the risk of fatal accident and on the calculation of the value or the price of the risk, more collectively named as "the value of a statistical life" (Hojman et al., 2005; Iraguen and Ortuzar, 2004; Rizzi and Ortuzar, 2003). Numerous Swedish studies were also interested in the individual WTP for a total elimination of the risk of fatal accidents or severe wounds (Andersson, 2007, 2008; Hultkrantz et al., 2006; Svensson and Johansson, 2010), taking support on the famous concept of "Vision zero" which aims to achieve a highway system with no fatalities or serious injuries in road traffic.

Our study broaches this theme in a more general way than the previous works on French data which were limited to the specific population of the young drivers from 18 to 25 years old (Lahatte et al., 2006; Lassarre et al., 2005). In these studies, the participants were asked to give their WTP to not experiment diverse consequences resulting from a road accident. An increasing relation between the level of WTP and the severity of the injuries likely to be avoided was revealing. Our study also distinguishes itself from that of Hensher et al. (2009) on Australian data which was more indirectly interested in this dimension of severity by using the method of discreet choices to reveal individual preferences (Louviere et al., 2000). More exactly, in the paper of Hensher et al. (2009), individuals 
were asked to choose among different choices of route for a particular trip. The attribute levels of each alternative (the probability of death or non-mortal physical wounds, the time of travel and the cost) vary according to a statistical design. The individual choices allowed to observe the making choices between different attribute level bundles and to estimate the WTP of the subjects for a reduction of their risk of fatal accident and not mortal injuries. The study showed that the average WTP is higher for mortal wounds than non-mortal ones. Moreover, a hierarchy in the levels of WTP is observed between the various levels of injuries severity: permanent injuries requiring hospitalization and engendering irreversible consequences present a WTP superior to major or minors injuries without impairment.

Our study tried to see if such conclusions were confirmed in the French context by using the declared preferences method as a technique of monetary valuation. We use more precisely the contingent valuation to estimate the value of a reduction of the risk of being victim of various types of non-mortal physical injuries following a road accident. We brought to light several phenomena. The most considerable one certainly remains the significant impact of the injuries severity on the WTP. This last one increases with the severity of the injuries likely to be incurred. The individuals are more ready to invest and grant to pay more important amounts of money to reduce their risk of heavy injuries in comparison to minor and moderate ones. These results follow on from previous studies and confirm the necessity to take into account the level of severity of injuries in studies of valuation of non-mortal consequences of traffic accidents.

The survey results also advance the strong influence of the individual accidental experience, that it is direct or indirect, on their WTP. The individuals having recently been victims of a road accident or whose close relatives has been hurt further to a road accident are more ready to invest to improve their road safety and reduce their risk of personal accident. This result strengthens the interest to lead casecontrol studies with inclusion of a damaged population. On the other hand, our study showed that the WTP tends to remain invariant regardless of the risk reduction ( $25 \%$ or $50 \%$ in our study). This confirms the presence of scale bias and the cognitive difficulty of the individuals to measure weak variations of risk (Carson et al., 2001; Hammitt and Graham, 1999) including when these are illustrated by concrete examples.

Regarding the apprehension of the individuals when facing road accidents, its effect on the contribution process remains ambiguous. The influence is present on the total sample of the participants but disappears after exclusion of the protesters. This dimension would deserve to be more developed during future studies. Indeed, studies on risk showed that people report making behavioural adaptations as a consequence of worry about accidents (Backer-Grondahl et al., 2009; Rundmo et al., 2011). The individual relative anxiety in front of road traffic and road accidents influences their use of means of transport and their behaviour as road users. The anxious people show themselves more selective on the choice of their means of transportation and care more about their road safety. It can seem relevant to pursue the efforts realized in this direction and take into account this dimension in future analyses of sensibility in devices of road safety.

\section{References}

Andersson, H. (2005) The value of safety as revealed in the Swedish car market: An application of the hedonic pricing approach. J Risk Uncertainty 30, 211-239.

Andersson, H. (2007) Willingness to pay for road safety and estimates of the risk of death: evidence from a Swedish contingent valuation study. Accident; analysis and prevention 39, 853-865. 
Andersson, H. (2008) Willingness to Pay for Car Safety: Evidence from Sweden. Environ Resour Econ 41, 579-594.

Andersson, H., Svensson, M. (2008) Cognitive ability and scale bias in the contingent valuation method. Environ Resour Econ 39, 481-495.

Arthur, W.B. (1981) The Economics of Risks to Life. American Economic Review. 71, 54-64.

Atkinson, S.E., Halvorsen, R. (1990) The Valuation of Risks to Life: Evidence from the Market for Automobiles. Review of Economics and Statistics . 72, 133-136.

Backer-Grondahl, A., Fyhri, A., Ulleberg, P., Amundsen, A.H. (2009) Accidents and Unpleasant Incidents: Worry in Transport and Prediction of Travel Behavior. Risk Anal 29, 1217-1226.

Beattie, J., Covey, J., Dolan, P., Hopkins, L., Jones-Lee, M., Loomes, G., Pidgeon, N., Robinson, A., Spencer, A. (1998) On the contingent valuation of safety and the safety of contingent valuation: Part I - Caveat investigator. J Risk Uncertainty 17, 5-25.

Carson, R.T., Flores, N.E., Meade, N.F. (2001) Contingent Valuation: Controversies and Evidence. Environmental and Resource Economics 19, 173-210.

Carthy, T., Chilton, S., Covey, D., Hopkins, L., Jones-Lee, M., Loomes, G., Pidgeon, N., Spencer, A. (1998) On the contingent valuation of safety and the safety of contingent valuation: Part 2 - The CV/SG "chained" approach. J Risk Uncertainty 17, 187-213.

Donaldson, C., Shackley, P., Abdalla, M., Miedzybrodzka, Z. (1995) Willingness to pay for antenatal carrier screening for cystic fibrosis. Health Econ 4, 439-452.

Dreyfus, M.K., Viscusi, W.K. (1995) Rates of Time Preference and Consumer Valuations of Automobile Safety and Fuel Efficiency. J Law Econ 38, 79-105.

Hammitt, J.K., Graham, J.D. (1999) Willingness to Pay for Health Protection: Inadequate Sensitivity to Probability? . J Risk Uncertainty 18, 33-62.

Harrison, G.W. (2006) Experimental evidence on alternative environmental valuation methods. Environ Resour Econ 34, 125-162.

Hensher, D.A., Rose, J.M., Ortuzar, J.D., Rizzi, L.I. (2009) Estimating the willingness to pay and value of risk reduction for car occupants in the road environment. Transport Res a-Pol 43, 692-707.

Hofler, R.A., List, J.A. (2004) Valuation on the frontier: Calibrating actual and hypothetical statements of value. Am J Agr Econ 86, 213-221.

Hojman, P., Ortúzar, J.d.D., Rizzi, L.I. (2005) On the joint valuation of averting fatal victims and serious injuries in highway accidents. Journal of Safety Research. 36, 337-386.

Hultkrantz, L., Lindberg, G., Andersson, C. (2006) The value of improved road safety. J Risk Uncertainty 32, 151-170.

Iraguen, P., Ortuzar, J.D. (2004) Willingness-to-pay for reducing fatal accident risk in urban areas: an Internet-based Web page stated preference survey. Accident Anal Prev 36, 513-524. 
Jeremic, V., Slovic, D., Radojicic, Z. (2012) Measuring Human Capital: A Statistical Approach. Actual Probl Econ, 359-363.

Jones-Lee, M., Loomes, G. (2003) Valuation of safety., Handbook of Transport and the Environment ed Elsevier, oxford.

Jorgensen, B.S., Syme, G.J., Bishop, B.J., Nancarrow, B.E. (1999) Protest responses in contingent valuation. Environ Resour Econ 14, 131-150.

Jorgensen, B.SWilson, M.A, Heberlein, T.A (2000) Fairness in the Contingent Valuation of Environmental Intergrated knowledge for ecological economics: a database to support ecosystem services evaluation. Ecological Economics, 36, 133-148.

Lahatte, A., Lassarre, S., Rozan, A. (2006) Analyse du consentement à payer pour éviter les conséquences d'un accident routier non mortel à l'aide de modèles de durée. Les Cahiers Scientifiques du Transport 50, 121-134.

Lassarre, S., Coquelet, C., Hoyau, P.-A. (2005) Jeunes automobilistes et risque routier: un panel multiobjectifs. Colloque francophone sur les sondages 2005.

Lindsey, G. (1994) Market-Models, Protest Bids, and Outliers in Contingent Valuation. J Water Res PIAsce 120, 121-129.

Louviere, J.J., Hensher, D.A., Swait, J.D. (2000) Stated Choice Methods: Analysis and Application.

Meyerhoff, J., Liebe, U. (2006) Protest Beliefs in Contingent Valuation: Explaining their Motivation. Ecological Economics, 57, 583-594.

Mishan, E.J. (1971) Evaluation of life and Limb: A theoretical approach. . Journal of Political Economy. 79, 687-745.

Rizzi, L.I., Ortuzar, J.d.D. (2003) Stated preference in the valuation of interurban road safety. Accident; analysis and prevention 35, 9-22.

Rundmo, T., Nordfjaern, T., Iversen, H.H., Oltedal, S., Jorgensen, S.H. (2011) The role of risk perception and other risk-related judgements in transportation mode use. Safety Sci 49, 226-235.

Strazzera, E., Scarpa, R., Calia, P., Garrod, G.D., Willis, K.G. (2003) Modelling zero values and protest responses in contingent valuation surveys. Appl Econ 35, 133-138.

Svensson, M., Johansson, M.V. (2010) Willingness to pay for private and public road safety in stated preference studies: Why the difference? Accident Anal Prev 42, 1205-1212.

Weinstein, M.C., Shepard, D.S., Pliskin, J.S. (1980) The Economic Value of Changing Mortality Probabilities: a Decision Theoretic Approach. . The Quaterly Journal of Economics. 94, 373-396.

WHO (2009) Global status report on road safety 2009. 